\title{
SIMULATION OF BRACKISH KARST SPRINGS OPERATION WITH THE MODKARST DETERMINISTIC MODEL
}

\author{
A. MARAMATHAS ${ }^{1 *}$ \\ I. GIALAMAS ${ }^{2}$ \\ A.G. BOUDOUVIS ${ }^{1}$
}

Selected from papers presented in $9^{\text {th }}$ International Conference on Environmental Science and Technology (9CEST2005)

1-3 September 2005, Rhodes island, Greece

\author{
${ }^{1}$ National Technical University of Athens \\ School of Chemical Engineering \\ Zografos Campus GR-15780 Athens, Greece \\ ${ }^{2}$ Hellenic Center for Marine Research \\ Agios Kosmas, Helliniko, 16604, Athens, Greece
}

*to whom all correspondence should be addressed e-mail: thamar@chemeng.ntua.gr

\begin{abstract}
A simulation is presented of the operation of brackish karst springs with the MODKARST deterministic mathematical model. Through this simulation, major issues regarding the operation mechanisms as well as the sustainable development of the springs are addressed and analyzed. The particular case analyzed is the Almiros brackish karst spring at Heraklion Crete in Greece and the Makaria brackish karst spring in Attica. Of concern are the following aspects: (a) The fractal characteristics of the Almiros karst formation, (b) the sea intrusion mechanism for the Almiros spring and the Makaria spring and (c) the choice of a suitable method for the sustainable development of the Almiros spring. It was found that the seawater intrusion in the Almiros karst-spring reservoir follows a power law, the exponent of which provides the fractal dimension of the system. Regarding sea intrusion, the spring becomes brackish due to the crossing of the tube, which carries the fresh water to the spring, with other tubes, carrying saltwater from the sea. MODKARST simulates the hydrograph along with the variation with time of the chloride concentration and correlates the discharges from the fresh water and the seawater tubes. The outcome is the relative importance of the two potential mechanisms for seawater intrusion, namely the density difference between fresh water and sea water and the venturi effect; it is found that the density difference dominates in the Almiros case while the Venturi effect dominates in the Makaria case. An important conclusion of the analysis is that raising the Almiros-spring water outlet could prevent the seawater intrusion; the location of the elevated outlet and the fresh water loss to the sea are estimated.
\end{abstract}

KEYWORDS: Brackish karst springs, Saltwater/freshwater relations, fractals

\section{NTRODUCTION}

The MODKARST model is a deterministic mathematical model that simulates the operation of brackish karst springs (Maramathas et al 2003). The input to the model is the rainfall data; the output is the hydrograph and the variation with time of the chloride concentration of the spring water. The model is based on a hydrodynamic analogue, which is sketched in Figure 1; each of the reservoirs shown is discharged to the tube that abuts to the spring. The governing equations of the model are mass and mechanical 
energy macroscopic balances; they are summarized in Table 1 along with the variables and the parameters of the model. More details are available in Maramathas et al. 2003. The model is used to simulate the operation of the Almiros karst spring at Heraklion Crete in Greece and the Makaria spring in Attica. The Almiros spring is located $10 \mathrm{~km}$ west of the city of Heraklion, at an elevation of about $4 \mathrm{~m}$ and at a distance of $1 \mathrm{~km}$ away from the sea. It is a periodically brackish karst spring, the discharge of which fluctuates between $4 \mathrm{~m}^{3} \mathrm{~s}^{-1}$ in the summer and $70-80 \mathrm{~m}^{3} \mathrm{~s}^{-1}$ in the winter. During almost $90 \%$ of the year the spring water is brackish due to seawater entering the spring's reservoir. The groundwater reservoir of the spring is structured by Mesozoic limestone with preferential permeability and small porosity. The "Makaria" spring is located $4 \mathrm{~km}$ east of the city of Marathon in Attica at a distance of $3.5 \mathrm{~km}$ from the sea. It is a brackish karst spring. The mean annual spring water quantity approaches $13.5 \times 106 \mathrm{~m} 3$. Cretaceous marbles structures the hydrogeological basin of the spring

Representative results of the Almiros-spring simulation and Makaria spring simulation are shown in Figures 2 and 3 and $2_{a}$ and $3_{a}$ respectively; the model predictions for the hydrograph and for the water chloride concentration versus time are compared with measurements.

Below are presented the three major results drawn from the simulation, with regard to the fractal characteristics of the Almiros karst formation, the sea intrusion mechanism for the Almiros spring and the Makaria spring and the sustainable development of the Almiros spring.

\section{MEASUREMENT OF THE FRACTAL CHARACTERISTICS OF THE ALMIROS KARST FORMATION}

Although predictions and measurements of the Almiros-spring hydrograph appear to be in good agreement (cf. Fig. 2), the corresponding comparisons of earlier predictions with measurements for chloride concentration revealed a discrepancy during the depletion periods. The discrepancy is shown in Fig. 4; it is not shown in Figure 3 because the corresponding theoretical predictions are obtained with an improved model - see below.

The spring exhibits an unexpected behaviour during depletion periods when there is no rain at all in Crete. The slope of the real spring water chloride concentration curve decreases, that is, the rate of increase of the chloride concentration of the spring water decreases during depletion periods. Moreover, in some cases, the chloride concentration decreases without any prior rainfall (Fig. 5).

The key to explain the behaviour of the spring with regard to chloride concentration during the depletion period is in the seawater intrusion into the karst system. For seawater to intrude, the pressure in the freshwater tubes must be lower than the pressure in the tubes carrying the saltwater from the sea. This is the case during the depletion periods and as the water level in the karst system reservoir decreases, due to the absence of rainfall, the flow ceases in an increasing number of freshwater tubes. As a result, the saltwater flow in the tubes, which come from the sea and meet the freshwater tubes, ceases too. Consequently, the rate of increase of the saltwater discharge to the system decreases and the rate of increase of the spring water chloride concentration decreases too.

To account for these effects, we adopt the reasonable assumption that the effective seawater outflow tube cross-section $\mathrm{S}_{3}$ (Table1) depends on the saturated volume of the karst reservoir and consequently on the water level in it. It comes out, through model fitting, that the best agreement between theoretical predictions and measurements is obtained with the power law $\mathrm{S}_{3}=\mathrm{aH}_{\mathrm{f}}^{\mathrm{b}}$. From further fitting it was found that $\mathrm{b}=0.59$. This value coincides with the fractal dimension of the system, which has been estimated following the analysis by Maramathas and Boudouvis 2004. 


\section{SEA INTRUSION MECHANISM}

From the hydrodynamic point of view, two are the potential mechanisms of seawater intrusion (Maramathas et al 2004, Breznic 1973):

1) The fresh water tube that abuts to the spring intersects another tube that comes from the sea and, as a result, the freshwater becomes brackish at the intersection, when the pressure in the freshwater tube is lower than the pressure in the seawater one - cf. Figure 6. This becomes possible if the intersection is at large enough depth below the sea, since the seawater density is larger than that of the freshwater.

2) The pressure in the freshwater tube at the intersection is less than that in the seawater due to geometry variations. In other words, the freshwater tube is quite narrow at the intersection and the pressure decreases due to the venturi effect - cf. Figure 7.

Actually, even though both mechanisms are active in any case, it is important to find the dominant one; this is valuable in deciding which is the suitable spring development method.

Deciding about the prevailing seawater intrusion mechanism amounts to determining the way in which the freshwater discharge $\left(Q_{1}\right.$ in Figures 1,2$)$ affects the seawater discharge $\left(Q_{2}\right.$ in Figures 1,2). Decreasing the water level over the discharge point of the spring's reservoir decreases freshwater discharge and the imbalance between saltwater and freshwater pressure increases; consequently, the seawater discharge increases. In this case the dominant intrusion mechanism is the difference between freshwater and seawater density.

On the other hand, there is a mutual augmentation between the seawater and freshwater discharge when the mechanism caused by the venturi effect prevails. This happens due to the intensification of the venturi effect, as a result of the increase of the freshwater velocity at the intersection between the seawater and the freshwater tube which thus provokes the increase of the freshwater discharge.

MODKARST calculates $Q_{1}$ and $Q_{2}$ in every run and uses them as intermediate variables to calculate the spring discharge and the chloride concentration of the spring water. Thus, a relationship between freshwater and saltwater discharge is obtained, as shown in Figure 8 for the Almiros spring and in Figure 9 for the Makaria spring. As it can be observed, the seawater discharge decreases when the freshwater discharge increases leading to the conclusion that the dominant sea intrusion mechanism for the Almiros spring is the difference between the seawater and freshwater density. On the other hand the seawater discharge increases when the freshwater discharge also increases in Makaria spring leading to the conclusion that the dominant sea intrusion mechanism for this spring is the Ventouri effect.

\section{THE DEVELOPMENT OF THE ALMIROS SPRING}

In some brackish springs it is possible for sea intrusion to be blocked by raising the water outlet point of the spring, through the construction of a dam in front of it as, in this way, the freshwater level in the spring reservoir will be raised and the resulting pressure increase will prevent sea intrusion (Maramathas 2004, Breznic 1973). This is an old but not very popular method since it raises two difficulties to be dealt with. First, the determination of the necessary vertical movement of the outlet and, second, the estimation of the freshwater loss (discharge) to the sea; the latter is caused since the tubes, that previously brought seawater to the spring reservoir, will bring fresh water to the sea after the elevation of the spring outlet which increased the freshwater pressure. MODKARST is a valuable tool in dealing with these difficulties.

One of the parameters of the model is the elevation of the spring's water outlet point. Consequently, the model can simulate the operation of the spring at different spring elevations. This has been applied to the Almiros spring for the years from 1989 to 1997 and the results are presented in Figures 10-12 and in Table 2. In Figures 10 and 11, the model predicted chloride variation versus time for the 10-meters and 20-meters spring elevation respectively, is compared to the real one at the real elevation ( $4 \mathrm{~m})$. As it can be 
observed, the quality of the water improves as the elevation of the water outlet point increases. In Figure12, the simulated percentage of the days throughout the year with fresh water versus the spring elevation for the hydrologic years 1989-90 to 1996-97 is presented. It comes out that the periods during which the spring offers fresh water become longer as the spring elevation increases. Moreover, the spring offers fresh water during the entire year when the elevation reaches the $22 \mathrm{~m}$. Finally, in Table 2, the model-calculated freshwater loss versus the spring elevation for the depletion period and the entire period, respectively, is presented.

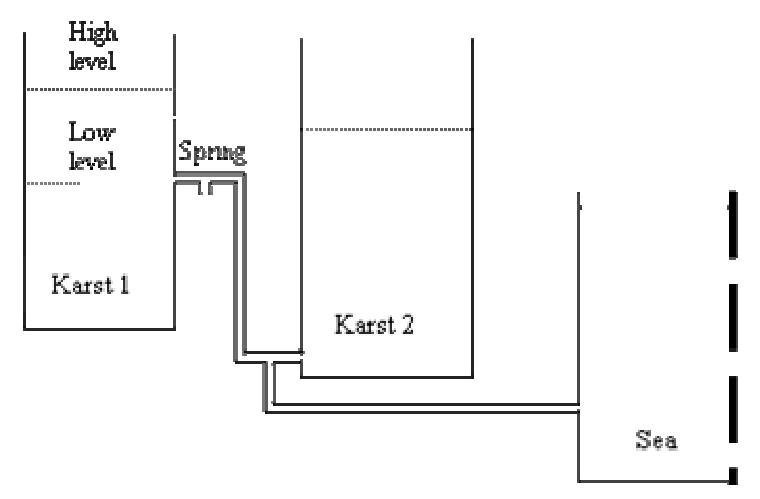

Figure 1. Hydrodynamic model of the karst springs

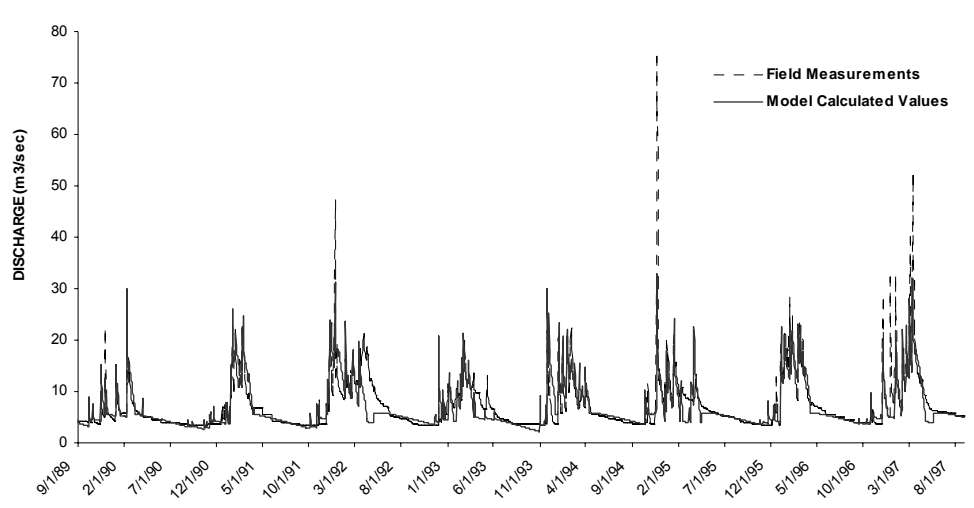

Figure 2. Comparison between the model-predicted hydrograph and field measurements for the Almiros spring

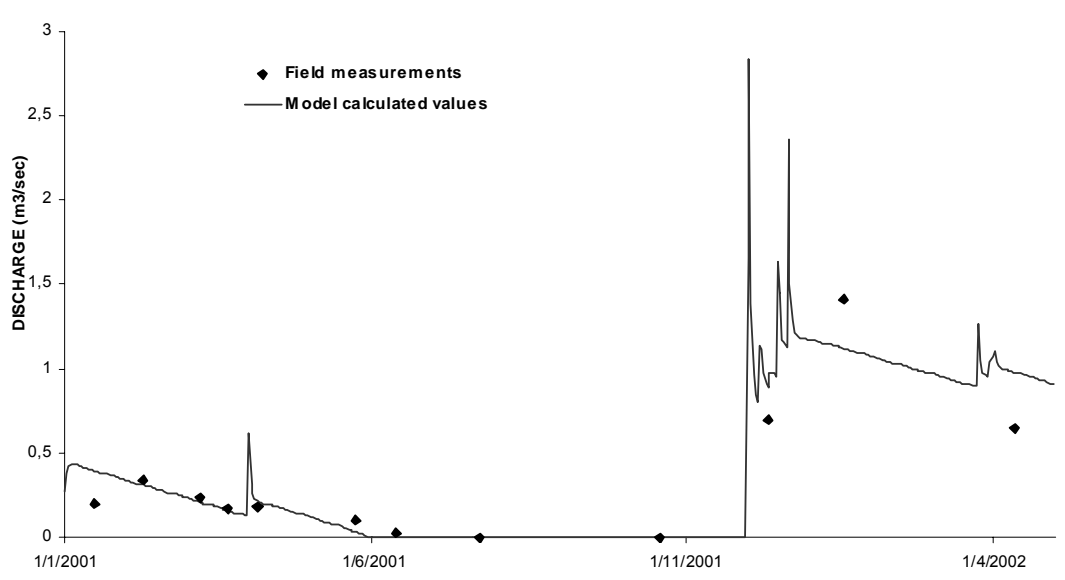

Figure 2a. Comparison between the model-predicted hydrograph and field measurements for the Makaria spring 
Table 1. Equations - Variables - Parameters of the model

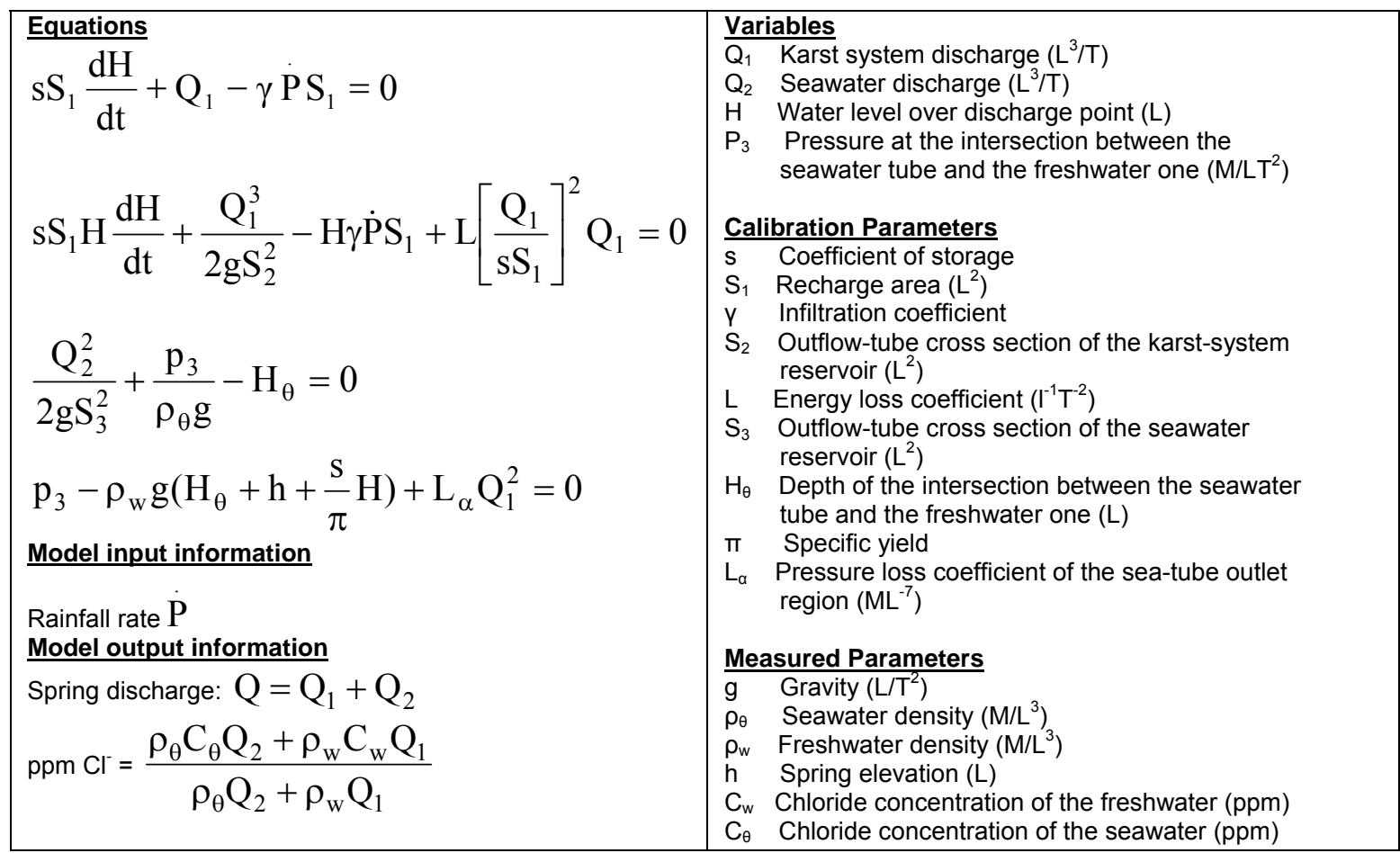

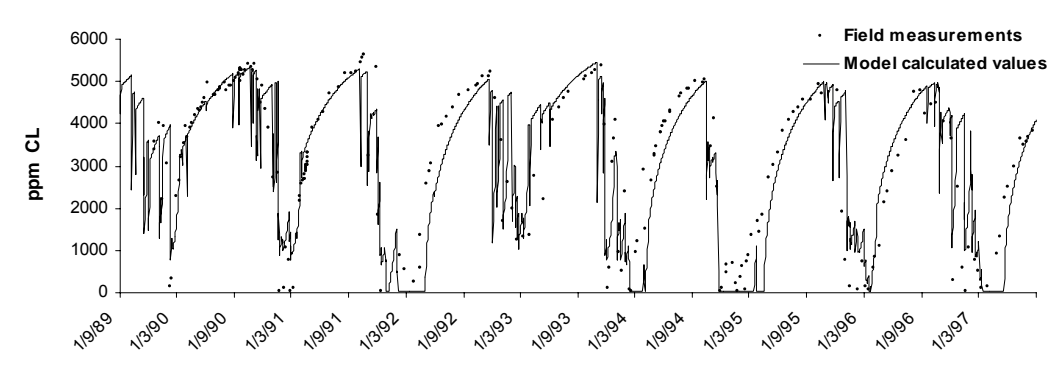

Figure 3. Comparison between the model-predicted water chloride concentration versus time and field measurements for the Almiros spring

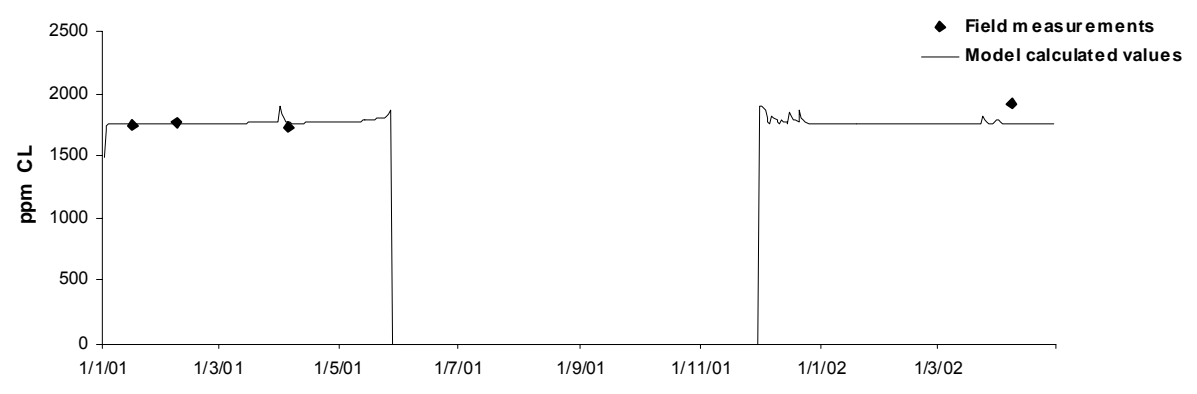

Figure 3a. Comparison between the model-predicted water chloride concentration versus time and field measurements for the Makaria spring 


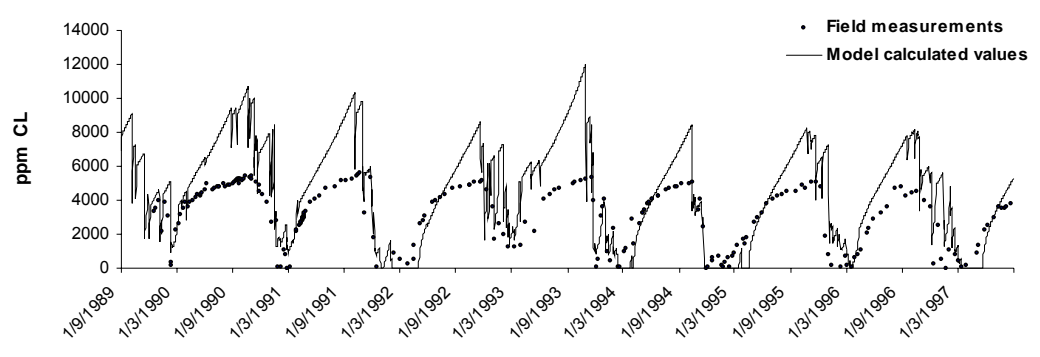

Figure 4. Comparison between predictions and measurements of water chloride concentration before the use of the power law. A discrepancy is observed during depletion periods

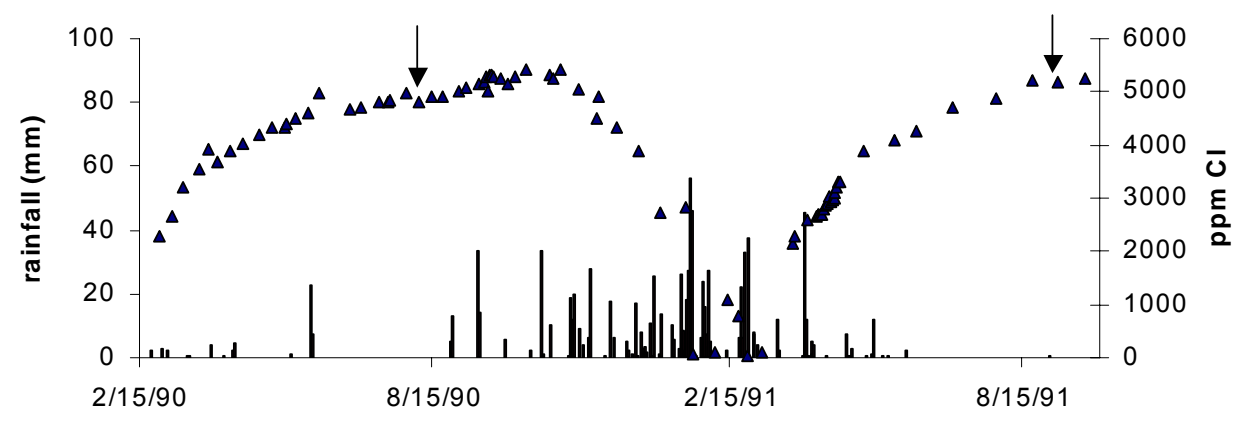

Figure 5. Rainfall and chloride concentration versus time for the Almiros spring. In two cases (arrows) the chloride concentration decreases without any prior rainfall

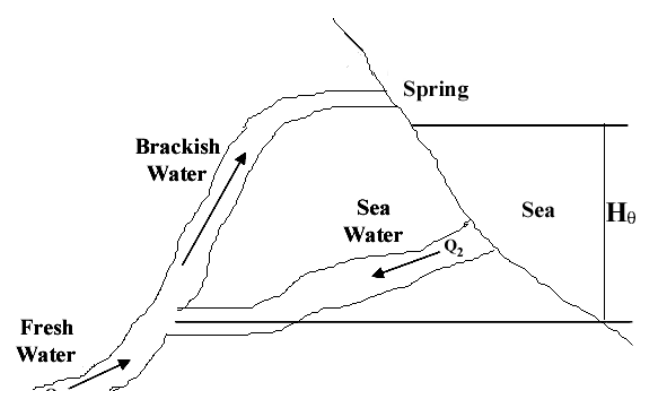

Figure 6. Sea intrusion mechanism of the spring based on the difference between the freshwater density and the seawater one

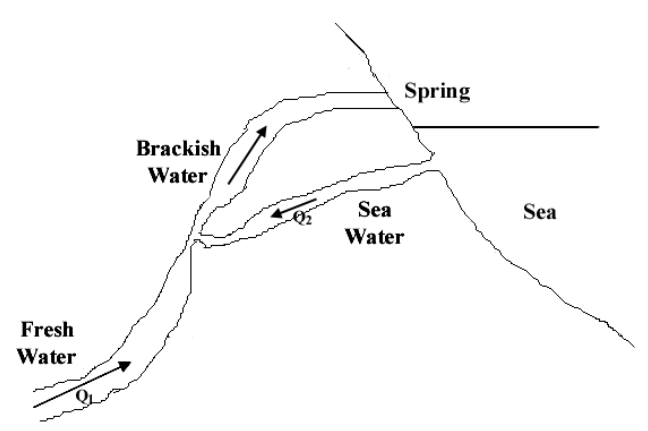

Figure 7. Sea intrusion mechanism of the spring based on the venture effect

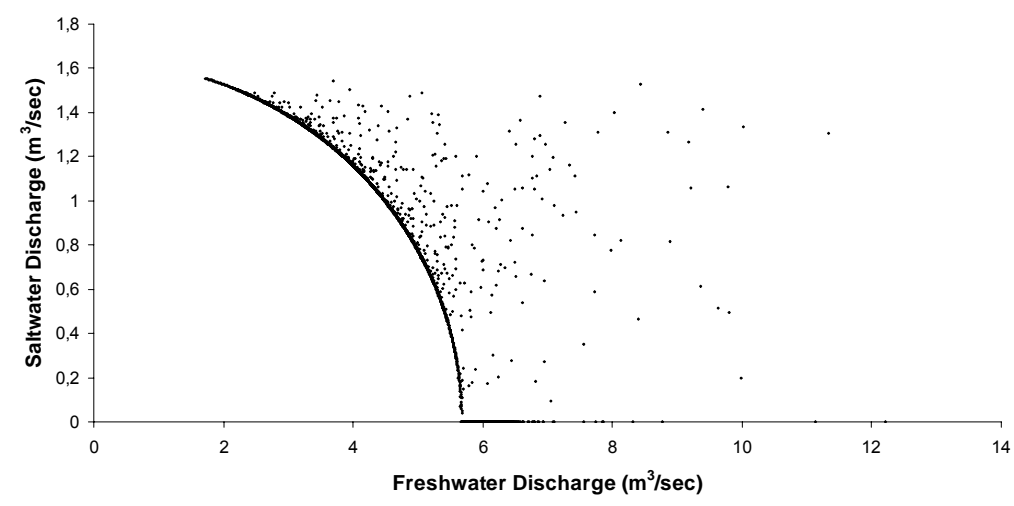

Figure 8. Saltwater discharge versus freshwater discharge for the Almiros spring.

Saltwater discharge increases when freshwater discharge decreases 


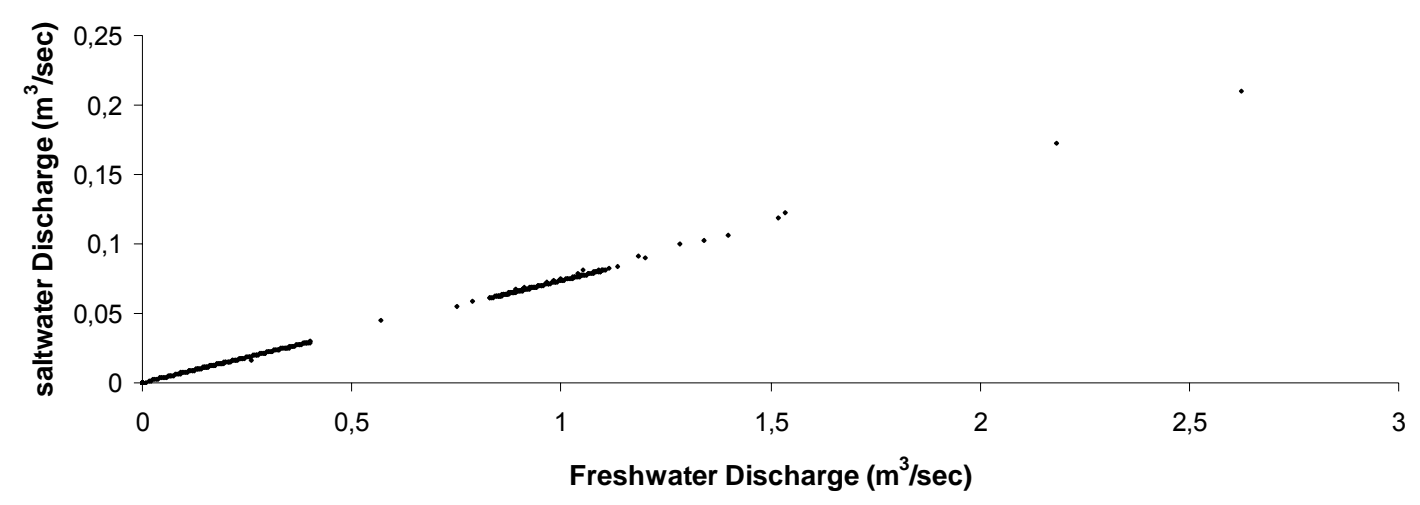

Figure 9. Saltwater discharge versus freshwater discharge for the "Makaria" spring. Saltwater discharge increases when freshwater discharge also increases.

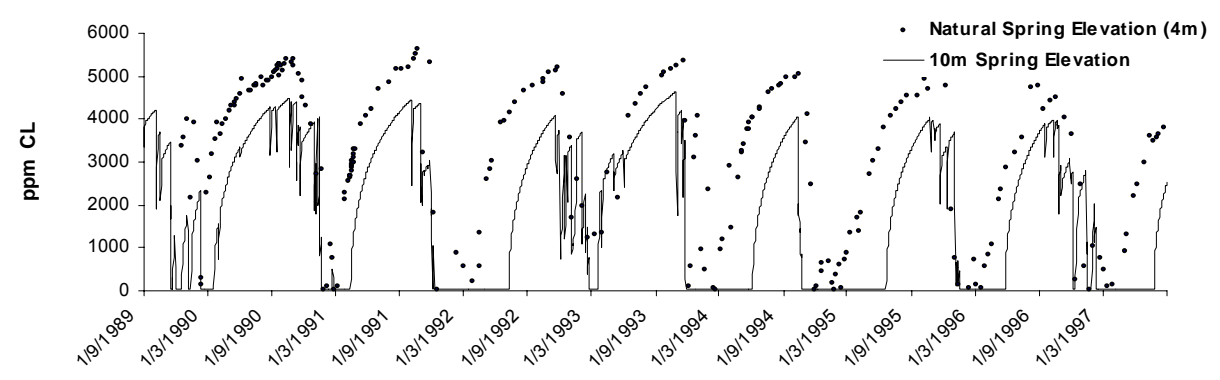

Figure 10. Comparison between the observed chloride concentration versus time at the real spring elevation point and the simulated one at $10 \mathrm{~m}$

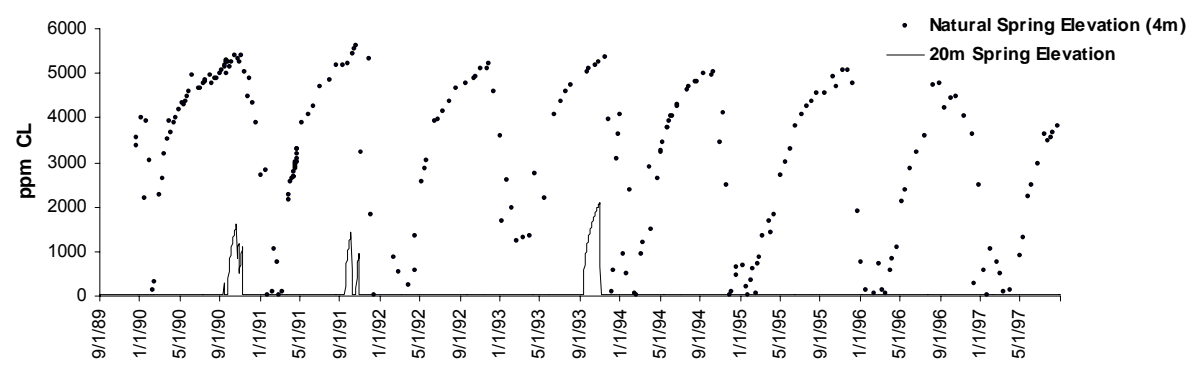

Figure 11. Comparison between the observed chloride concentration versus time at the real spring elevation point and the simulated one at $20 \mathrm{~m}$

\section{CONCLUSIONS}

The simulation of the operation of brackish karst springs with the deterministic MODKARST model provides clear physical insights to the karst system. The Almiros spring simulation has given information about the fractal nature of the karst system, the seawater intrusion mechanism and the choice of a suitable development method. The dominant sea intrusion mechanism for the Almiros spring is the difference between the freshwater and seawater densities. The sea intrusion could be prevented by raising the spring water outlet location, through the construction of a small dam; an estimated elevation of $22 \mathrm{~m}$ appears to be the best choice. The Makaria spring simulation has given information about the dominant sea intrusion mechanism that is the Venturi effect. 
Table 2. Spring freshwater loss (\%)

$\begin{array}{ccc}\text { Elevation } & \text { Whole period } & \text { Depletion period } \\ 4 & 0,00 & 0,00 \\ 5 & 0,03 & 0,00 \\ 6 & 0,81 & 0,00 \\ 7 & 1,70 & 0,50 \\ 8 & 2,96 & 1,02 \\ 9 & 4,24 & 2,32 \\ 10 & 5,55 & 4,06 \\ 11 & 6,99 & 6,39 \\ 12 & 8,53 & 8,93 \\ 13 & 9,98 & 11,63 \\ 14 & 11,50 & 13,91 \\ 15 & 13,15 & 17,05 \\ 16 & 14,68 & 20,83 \\ 17 & 16,21 & 24,26 \\ 18 & 17,68 & 27,75 \\ 19 & 18,97 & 30,38 \\ 20 & 19,96 & 33,22 \\ 21 & 20,74 & 34,75 \\ 22 & 21,23 & 35,33\end{array}$

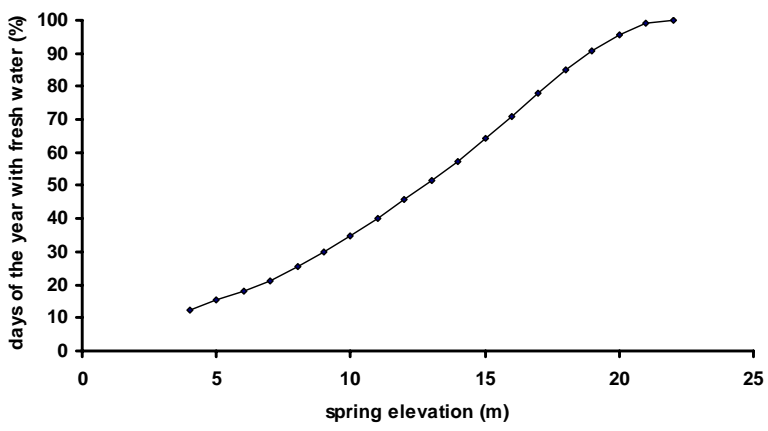

Figure. 12. Days during the year (\%) with fresh water versus spring elevation

\section{REFERENCES}

1. Breznic, M. (1973) The origin of brackish Karst springs and their development. Col. Razpr. In Por. 16 Knjig, pp.83-186.

2. Maramathas, A., Pergialiotis, P., Gialamas, I., 2004, Estimation of sea intrusion mechanism of brackish karst springs by their simulation with the "MODKARST" deterministic model, Hydrogeology Journal (in print).

3. Maramathas, A. Boudouvis, A.G., 2004, Manifestation and measurement of the fractal characteristics of karst hydrogeological formations Advances in Water Resources (in print).

4. Maramathas, A., Maroulis, Z., Marinos-Kouris, D., 2003, A Brackish Karstic Springs Model. Application on Almiros Crete Greece, Ground Water Volume 41 No 5 pp 608-620.

5. Maramathas, A., 2004, A new approach for the development and management of brackish karst springs Hydrogeology Journal (submitted). 